ARTíCULOS DE INVESTIGACIÓN

\title{
La legitimación activa en procesos correctivos y sancionatorios de libre competencia
}

\author{
Standing to sue in corrective and civil penalty \\ procedures in competition law \\ Jaime Arancibia Mattar \\ Universidad de los Andes, Chile
}

\begin{abstract}
RES UMEN
El objetivo de este trabajo es analizar la legitimación activa en procesos correctivos y sancionatorios seguidos ante el Tribunal de Defensa de la Libre Competencia. El método utilizado consiste en analizar todos los fallos nacionales sobre la materia, la historia de la legislación respectiva y tanto los referentes doctrinales como jurisprudenciales más importantes en Estados Unidos y la Unión Europea. Se concluye que la legitimación activa es ordinaria con respecto a la sociedad, representada por el Fiscal Nacional Económico, y extraordinaria con respecto a los agentes del mercado en la medida que logren acreditar. Estos últimos ejercen una acción a nombre propio para el amparo de un interés ajeno (público) en virtud de una habilitación legal expresa. Esta legitimación no es popular porque exige la afectación de un interés como comprador o vendedor del mercado concernido. Ellos podrían actuar mediante un representante común o creando un grupo o asociación que sea titular de un interés supraindividual calificado por ley.
\end{abstract}

\section{PALABRAS CLAVE}

Legitimación activa $\cdot$ libre competencia $\cdot$ sancionatorio $\cdot$ tribunal $\cdot$ litigación.

\section{A B S T RACT}

The purpose of this paper is to analyze standing to sue in corrective and sanctioning proceedings before the Competition Tribunal. Its method has consisted of analyzing all domestic judgments on the subject, the history of the relevant legislation, and the most important secondary sources and case law in the United States and the European Union. It is concluded that standing to sue in this field is «ordinary» with respect to the community, represented by the National Economic Prosecutor, and «extraordinary» with respect to market agents. They bring actions in their own name for the protection of another's 
interest (public) by virtue of an express legal authorization. This standing is not "popular» because it requires the injury of an interest as buyer or seller of the relevant market. They could litigate through a common representative or by creating a group or association that is the holder of a supra-individual interest, as long as it this is expressly recognised by statute.

KEY WORDS

Standing to sue $\cdot$ antitrust-competition $\cdot$ penalties $\cdot$ tribunal $\cdot$ litigation.

\section{INTRODUCCIÓN}

Este trabajo tiene por objeto analizar la legitimación activa para incoar procedimientos contenciosos correctivos y sancionatorios ante el Tribunal de Defensa de Libre Competencia (TDLC). La ausencia de criterios dogmáticos sobre esta materia anima a contribuir con propuestas acerca de las categorías procesales aplicables y del método o test necesario para identificar al titular legítimo de esta acción, sobre todo considerando algunas inconsistencias o confusiones que se observan en el foro y en la jurisprudencia nacional.

En particular, no existe claridad con respecto a si se trata de una legitimación activa ordinaria o extraordinaria, de objeto disponible o indisponible, o si el instituto aplicable es uno adjetivo de representación procesal del titular del interés. Si bien hay coincidencia en que el interés legítimo para accionar no es popular sino calificado, la existencia de este último es dudosa ante hipótesis más sofisticadas de traspaso de perjuicios (pass on), restricciones a la innovación, ausencia de sobreprecio o beneficios ilegales a sujetos de buena fe. El problema se ve agudizado en el caso de cuerpos intermedios titulares de intereses difusos y colectivos, donde suele confundirse la triple calidad bajo la cual pueden comparecer en el proceso: afectado directo, representante de afectados individuales o titular de un interés supraindividual.

Puesto que el objeto de estos procesos es la protección del interés público en la libre competencia, este estudio sostendrá, en primer lugar, que la legitimación activa ordinaria en esta materia solo corresponde a la sociedad en su conjunto, representada por el Fiscal Nacional Económico

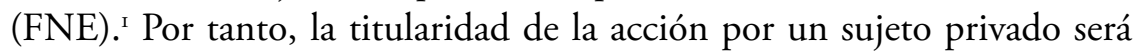
siempre una hipótesis de legitimación extraordinaria que debe ser definida por ley de modo expreso en razón de su excepcionalidad.

Dado que la legitimación extraordinaria supone la acción en nombre propio para impetrar el amparo de un interés ajeno, es preciso distinguirla de hipótesis prima facie similares como la representación procesal de ter-

\footnotetext{
${ }^{1}$ Artículo 39 letra b) del DL 2II de 1973.
} 
ceros. Además, su excepcionalidad determina que la identificación de los sujetos habilitados por ley debe ser estricta. Esto conlleva que el interés exigido para pertenecer a dicha categoría supone, en el caso de los individuos, afectación efectiva; y, en el caso de los intereses colectivos o difusos, representatividad suficiente y autonomía procesal del titular con respecto a los afectados directos.

Para efectos de fundamentar estas propuestas, este trabajo se dividirá en cinco secciones. La primera destacará que el objeto del proceso es el interés público en la libre competencia, de origen legal y carácter indisponible. La sección siguiente abordará el régimen binario de legitimación activa: pública ordinaria o privada extraordinaria. La sección posterior explicará la distinción dogmática entre representación procesal y legitimación activa. La última sección abordará los requisitos de legitimación activa vinculados con el interés colectivo o difuso esgrimido.

\section{El OBJETO DEL PROCESO ES LA AFECTACiÓN DEL INTERÉS PÚBLICO EN LA LIBRE COMPETENCIA}

La normativa de libre competencia en Chile, contenida en el DL 2II de 1973, tiene por objeto "promover y defender la libre competencia en los mercados» (artículo I). Esta finalidad se cumple, principalmente, a través del proceso correctivo y sancionador de libre competencia seguido ante el TDLC, que permite prohibir, corregir, reprimir y sancionar los atentados en contra de este bien jurídico (artículo I).

La finalidad de este procedimiento es, entonces, el resguardo de un interés público calificado por la ley. Verificado el presupuesto material de lesión de este bien, el Estado tiene el deber indeclinable de resguardarlo para la sola verificación y realización del derecho objetivo que lo ampara, más allá del agravio a un sujeto particular. En este sentido, la función radical o nuclear de la libre competencia trasciende la esfera de lo privado para situarse en el ámbito de lo público, lo común, lo que importa y concierne a todos.

Esta protección in abstracto o per se de la libre competencia obedece a su naturaleza de bien esencial para la satisfacción de intereses diversos. En Chile, este tema ha sido bien tratado por Valdés Prieto. ${ }^{2}$ Específicamente, la libre competencia no solo asegura el derecho subjetivo de competencia mercantil, sino también, en armonía necesaria con este, protege el interés de los consumidores, evita el enriquecimiento injusto del oferente,

2 VAldés Prieto, Domingo, Libre competencia y monopolio (Santiago, Editorial Jurídica de Chile, 2006), pp. 178-207. 
y da lugar a precios verdaderos que contribuyen a la provisión eficiente de bienes y a la justa distribución de beneficios y gravámenes económicos.

Por lo mismo, el objeto del proceso correctivo o sancionador de libre competencia, es decir, la cosa sobre la que versa el proceso y que exige la intervención del juez, no son los intereses de sujetos jurídicos concretos, sino el mismo «hecho, acto o convención que impida, restrinja o entorpezca la libre competencia, o que tienda a producir dichos efectos» (artículo 3). En otras palabras, el proceso no tiene por objeto la vulneración de derechos de agentes económicos, sino las «situaciones» (artículo I8, número I) o «asuntos» (artículo I8, número 2) que pudieren afectar, de modo objetivo, el bien jurídico.

En este sentido, el TDLC ha declarado que los litigios en libre competencia «no están encaminados a reconocer los derechos subjetivos o individuales de quienes intervienen en ellos, sino a sancionar, prevenir, corregir o prohibir los atentados a la libre competencia». ${ }^{3}$ Asimismo, la Corte Suprema de Estados Unidos ha declarado que "el propósito de las leyes de libre competencia [...] es la protección de la competencia, y no de los competidoress. ${ }^{4}$ De manera que, en procesos estrictamente correctivos o sancionatorios, la protección jurisdiccional de tales realidades subjetivas se logra únicamente de modo indirecto, reflejo o mediato, es decir, por efecto de la satisfacción de un interés público en la vigencia del derecho objetivo.

Sin perjuicio de lo anterior, dada su importancia, el legislador ha considerado insuficiente la tutela de la libre competencia a través actuaciones de la FNE y ha dotado excepcionalmente a sujetos particulares de legitimación activa pese a no ser titulares del interés público afectado. Esta realidad permite calificar la legitimación activa en este proceso como pública ordinaria o privada extraordinaria.

\section{LA LEGITIMACIÓN ACTIVA EN EL PROCESO SANCIONADOR}

O CORRECTIVO DE LIBRE COMPETENCIA PUEDE SER PÚBLICA ORDINARIA

O PRIVADA EXTRAORDINARIA

Como se sabe, la legitimación procesal es la cualidad para ser justa parte en un proceso instando por el amparo de los derechos o intereses legítimos. Por eso, ha sido definida por la Corte Suprema como «la aptitud para ser parte en un proceso concreto y obtener una sentencia favorable a su

3 TDLC, sentencia rol II4/20II, del I7 de noviembre de 20II, considerando decimosexto.

${ }^{4}$ Leegin Creative Leather Pros., Inc. v. PSKS, Inc., 55I U.S. 877, 906 (2007) (citando a Atl. Richfield Co. con USA Petroleum Co., 495 U.S. 328, 338 (1990)). 
pretensión».5 Viene dada por la relación del sujeto — parte- con la situación jurídica sustancial o material que se deduce en juicio - objeto-. En consecuencia, como señala Cordón Moreno, los «sujetos legitimados son [...] aquellos que en virtud de su conexión con la resolución pedida en la demanda, deben hallarse presentes en juicio para que el juez pueda entrar en el conocimiento del fondo de la misma». ${ }^{6}$

En este sentido, la legitimación constituye un presupuesto de la acción de carácter sustancial, necesario para que exista un pronunciamiento del juez acerca del fondo del asunto deducido. Es de carácter objetivo, ya que se basa en la posición de una persona con respecto al objeto material del acto. No se trata, por tanto, de un presupuesto formal como la capacidad, necesario para que exista juicio. En ausencia de legitimación activa o pasiva, la acción debe ser rechazada por falta de un requisito sine qua non para el juzgamiento. ${ }^{7}$

En los procesos destinados a la satisfacción de un interés público, la legitimación activa corresponde, por regla general, a la sociedad como titular de dicho interés, la cual acciona por medio de su representante. En materia de libre competencia, el representante del titular del interés social es la FNE, según lo indica el artículo 39, letra b) del DL 2II: "actuar como parte, representando el interés general de la colectividad en el orden económico, ante el Tribunal de Defensa de la Libre Competencia y los tribunales de justicia, con todos los deberes y atribuciones que le correspondan en esa calidad».

Sin embargo, la ley también concede legitimación activa a sujetos privados. Específicamente, el DL 2II se refiere a ellos como "parte», en contraposición a la FNE (artículo I8, número I), y denomina su acción como "demanda de algún particular» (artículo 20, inciso segundo). ${ }^{8}$

s Corte Suprema, sentencia rol 490-2013, del 23 de julio de 2013, considerando decimotercero.

${ }^{6}$ Cordón Moreno, Faustino, Anotaciones acerca de la legitimación, en Revista de Derecho Procesal Iberoamericana 2 (1979), p. 316.

7 La jurisprudencia nacional sobre libre competencia ha hecho suyos estos presupuestos doctrinales, al declarar que la legitimación activa corresponde a "la titularidad de la acción", y que "se encuentra referida a la relación del sujeto con la situación jurídica sustancial comprometida en el juicio, de la que surge un interés que lo habilita para ejercerla, impetrando su tutela ante el órgano jurisdiccional [...] Como quiera, se trata de un presupuesto vinculado a la situación que se controvierte en la litis, constituyendo un presupuesto de fondo para la procedencia de la acción y configura una excepción perentoria de consideración previa con respecto a todo otro análisis relativo a aspectos sustanciales de la controversia, no puede sino convenirse en que su ausencia es idónea para provocar por si sola y necesariamente la desestimación de la demanda, al encontrarse quien la deduce desprovisto de interés en la decisión del pleito». Véase Corte Suprema, sentencia rol $780-2008$, del 28 de agosto de 2008, considerando $29 .^{\circ}$.

${ }^{8}$ Cfr. TDLC, sentencias roles 86/2009, considerando noveno; II $4 / 201$, considerando decimoquinto a decimoséptimo; I32, considerando $67 . .^{\circ} ; \mathrm{I33} / 2014$, considerando decimo- 
Dado que la normativa de libre competencia no alude directamente al tipo de legitimación activa de la que gozan los particulares, surge la interrogante acerca de la categoría dogmática que habilita la interposición de la acción. Al respecto, es preciso descartar que corresponda a una legitimación ordinaria, ya que, como dijimos, el proceso no tiene por objeto la protección de un derecho o interés subjetivo del particular, sino el interés público en la libre competencia. Debemos descartar, además, que los sujetos privados actúen como representantes del titular del interés público, pues dicha función ha sido conferida exclusivamente a la FNE. 9

En nuestra opinión, la legitimación activa de los particulares corresponde a una legitimación activa extraordinaria o titularidad de la acción a nombre propio para obtener la protección de un interés ajeno. En palabras del TDLC, "la legitimidad activa de las partes no puede estar referida a la existencia de "derechos subjetivos" comprometidos en los resultados, sino que debe construirse sobre la base del "interés legitimo" ". ${ }^{10}$

Por tratarse de una legitimación extraordinaria, su establecimiento es de derecho estricto, es decir, no admite interpretaciones extensivas. Cuando el interés cuya protección de demanda es ajeno, como es el caso, opera una lógica inversa a la legitimación ordinaria, pues la regla general es la falta de legitimación salvo excepciones precisas. Por eso es que no compartimos la declaración del TDLC, a propósito de la legitimación extraordinaria de los consumidores, de que «las limitaciones al derecho de acción, en materia de derecho público, son de derecho estricto y deben estar expresamente establecidas en la ley»." ${ }^{\text {. }}$ Lo verdaderamente estricto en estos casos es la posibilidad de accionar y no la limitación al derecho de acción.

En cuanto a su contenido, la legitimación activa extraordinaria envuelve únicamente el ejercicio de las facultades procesales de ius acussandi (acusar o incoar el inicio del procedimiento) y ius persequendi (perseguir o promover el proceso). De modo que el desistimiento de la acción no conlleva una disposición del interés que se buscaba proteger sino únicamente de las prerrogativas procesales del actor. En otras palabras, el legitimado activo extraordinario es titular de la acción pero no del interés cuyo ampa-

primero y decimosegundo; 156/2017, considerando decimosexto. Ver también, TDLC, sentencia 158 , considerando décimo, con respecto a la legitimación activa para acusar el incumplimiento de resoluciones o avenimientos.

9 TDLC, sentencias roles 98/20Io, considerando decimonoveno y $22 .{ }^{\circ}$; $146 / 2015$, considerando décimo y 21. ${ }^{\circ}$. En igual sentido, Corte Suprema, sentencia rol 2.680-2010, considerando cuarto.

ro TDLC, sentencia rol II4/20II, considerando decimosexto.

II TDLC, sentencia rol I33/20I4 considerando decimocuarto. 
ro pretende; de alguna manera, viene a sustituir excepcionalmente a este último en el ejercicio de la acción, solo porque la ley así lo permite.

\section{El interés legitimo necesario para accionar}

Aclarada esta cuestión, surge una segunda interrogante acerca de si la legitimación extraordinaria o el «interés legítimo» para accionar es popular o cualificado, esto es, si la titularidad de la acción está reservada a cualquier sujeto por el solo interés en proteger la legalidad objetiva, o solo a aquellos que se han visto afectados producto de la infracción legal. Si bien el DL 2II no se pronuncia directamente al respecto, sostenemos, en línea con la jurisprudencia, ${ }^{\mathrm{I}}$ que se trata de una legitimación cualificada.

Podemos mencionar, en primer lugar, un argumento de lege lata. El DL 2II permite la intervención de terceros en procedimientos no contenciosos siempre y cuando "tengan interés legitimo en los hechos, actos o contratos" (artículo i8, número 2), de lo que es posible deducir que la legitimación corresponde a agentes económicos que tienen intereses individuales comprometidos en la operación respectiva. Si bien esta norma no es aplicable a los procedimientos contenciosos, su importancia para nuestro argumento es a fortiori, pues el TDLC ha declarado que la legitimación activa en los mismos debe ser más estricta aún. ${ }^{13}$

Además, ya que la legitimación extraordinaria popular es aún más excepcional que la individual, solo procede ante el reconocimiento explícito del legislador, ${ }^{14}$ circunstancia que no ocurre en la libre competencia doméstica.

En cuanto al contenido preciso del interés legítimo para demandar, la jurisprudencia ha insistido en la afectación de la posición jurídica del actor como oferente o consumidor del mercado concernido. En efecto, se reconoce legitimación activa extraordinaria a los sujetos "afectados directa o indirectamente por el deficiente funcionamiento del mercado que la infracción ocasionare», ${ }^{15}$ a aquel que "participe actual o potencialmente en el mer-

${ }_{12}$ TDLC, sentencia rol I46/20I5, considerando décimo. Ver también TDLC, sentencia rol 98/20Io, considerando decimonoveno y 22. ${ }^{\circ}$. En igual sentido, Corte Suprema, sentencia rol 2.680-20I0, considerando cuarto.

${ }_{13}$ TDLC, sentencia rol 146/2015, considerando vigésimo.

${ }^{14}$ Cordón Moreno, Faustino, La legitimación en el proceso contencioso-administrativo (Pamplona, Ediciones Universidad de Navarra S.A., 1979), p. I46-I47: «Lo primero que se observa es que el actor popular posee una legitimación originaria otorgada directamente por la ley".

is TDLC, sentencia rol 86/2009, considerando $25 .^{\circ}$. 
cado que resultaría afectado con las conductas denunciadas", ${ }^{16}$ que "posea la calidad de sujeto pasivo inmediato de una conducta determinada que pueda constituir una infracción al Decreto Ley $2 I I »,{ }^{17}$ o que sea "víctima directa de un atentado en contra de la libre competencia», para lo cual «ha de participar actual o potencialmente en el mercado que es directamente afectado por la presunta actividad anticompetitiva de otro agente económico, o bien en otros mercados conexos que puedan razonablemente verse afectados en forma indirecta por esa actividad supuestamente antijurídica». ${ }^{18}$

En otras palabras, para gozar de legitimidad activa, el demandante debe acusar acciones u omisiones que «hayan podido, razonablemente, afectarle de manera directa o indirecta en su capacidad de desenvolverse competitivamente, en tanto agente económico, en algún mercado determinado». ${ }^{19}$ Además, sostiene el Tribunal, "dado que infringe la libre competencia no solo el que actualmente la impide, restringe o entorpece, sino también quien tiende a producir dichos efectos, el interés legítimo corresponde tanto a quienes tales efectos alcanzan, como a las personas que estos tiendan razonablemente a afectarn..$^{\circ}$

Aplicando estos parámetros de legitimación, el TDLC ha declarado como titulares particulares de la acción «a todas aquellas personas que participan en los mercados afectados por las conductas en cuestión — sea en calidad de competidores, proveedores o clientes-o que podrian participar en ellos de no mediar las conductas anticompetitivas de que se traten. ${ }^{21}$ Por ejemplo, "las empresas que compitan o pretendan competir con ellos [autores de los hechos denunciados]", ${ }^{22}$ como "los competidores actuales o potenciales del acaparadon,${ }^{23}$ del adjudicatario de una licitación de contrato ${ }^{24} \mathrm{o}$ de espectro radioeléctrico; ${ }^{25}$ aquellos que hayan "participado activamente, en calidad de agente económico concernido por el proyecto consultado en el procedimiento que estableció las condiciones necesarias para que este naciera válido a la vida del derecho»; ${ }^{6} \mathrm{o}$ aquellos que alegan haber sido discriminados arbitraria-

\footnotetext{
${ }^{16}$ Corte Suprema, sentencia rol 2.680-20Io, considerando cuarto.

17 TDLC, sentencia rol 98/20Io, considerando decimoctavo.

${ }^{18}$ Ibid. Ver también TDLC, sentencia rol $146 / 2015$, considerando decimotercero.

19 TDLC, sentencia rol 98/2010, considerando $22 .{ }^{\circ}$.

${ }_{20}$ TDLC, sentencia rol II4/2OII, considerando decimoctavo.

${ }^{21}$ Ibid. Ver también TDLC, sentencia rol 132/2013, considerando 66. ${ }^{\circ}$.

${ }_{22}$ TDLC, sentencia rol 146/20I5, considerando decimoctavo.

${ }_{23}$ Ibid.

${ }^{24}$ TDLC, sentencia rol I68/2019, considerando cuarto.

${ }_{25}$ TDLC, sentencia rol 156/2017, considerando decimoséptimo y decimoctavo.

${ }_{26}$ TDLC, sentencia rol 86/2009, considerando octavo.
} 
mente por una empresa o autoridad en relación con sus competidores. ${ }^{27}$ Incluye, además, a los consumidores considerados individualmente, ${ }^{28} \mathrm{sin}$ perjuicio de lo que diremos sobre las asociaciones de consumidores más adelante.

Por lo mismo, la jurisprudencia ha rechazado la titularidad de la acción por parte de sujetos con respecto a los cuales «no se ha acreditado en el proceso la intervención efectiva [...] en algún mercado afectado por las presuntas infracciones denunciadas»; ${ }^{29}$ que han accionado "sin explicar cómo el interés individual, colectivo o difuso de los consumidores podría verse afectado inmediata y directamente por dicha conducta»;30 o que tengan participación accionaria en una sociedad "constituida en una fecha posterior a los hechos que fundamentan la demanda». ${ }^{3 \mathrm{I}}$

\section{Hipótesis más sofisticadas de interés legitimo}

Siendo este el status quaestionis del interés legítimo que habilita para accionar, conviene abordar también problemas de legitimación más sofisticados, mencionados por CRANE, ${ }^{32}$ que podrían plantearse en el futuro. Por ejemplo, el de los compradores indirectos de un producto. ¿Quién es el realmente afectado por una conducta anticompetitiva cuyos efectos perniciosos ( $v$. $g r$. sobreprecio) son traspasados por cada agente de la cadena comercial hasta llegar al último eslabón? ¿Tiene legitimación activa como "afectado» un comprador que pudo traspasar el costo del eventual ilícito al comprador siguiente?

En Estados Unidos, por ejemplo, el comprador directo del infractor goza de legitimación activa pese a haber transferido el costo del daño al adquirente siguiente, ${ }^{33}$ que carece de legitimación a nivel federal. ${ }^{34}$ CRANE explica que esta restricción se debe en parte a que, a nivel judicial, la satisfacción del interés público en la libre competencia es tan importante como la compensación de los sujetos privados, razón por la cual el verdadero legitimado sería el destinatario inmediato del acto ilegal y de los

${ }_{27}$ TDLC, sentencia rol I49/2016, considerando $30 .^{\circ}$.

${ }_{28}$ TDLC, sentencia rol $\mathrm{I3} 3 / 2 \mathrm{OI} 4$, considerando decimocatorce.

29 TDLC, sentencias roles 98/20IO, considerando $2 \mathrm{I}^{\circ}{ }^{\circ}, \mathrm{I} 46 / 2015$, considerando decimoctavo. Ver también Corte Suprema, sentencia rol 2.680-20Io, considerando cuarto.

30 TDLC, sentencia rol $146 / 2015$, considerando $2 \mathrm{I}^{\circ}{ }^{\circ}$.

${ }^{31}$ TDLC, sentencia rol 98/20IO, considerando 21. ${ }^{\circ}$.

${ }^{32}$ Crane, Daniel, Optimizing Private Antitrust Enforcement, en Vanderbilt Law Review 63 (2019) 3, pp. 679 ss.

${ }_{33}$ Cfr. Hanover Shoe, Inc. con United Shoe Mach. Corp., 392 U.S. 48I (1968).

${ }^{34}$ Cfr. Ill. Brick Co. con Illinois, 43I U.S. 720 (1977). 
perjuicios que este genera. En cambio, explica él, los regímenes procesales que distinguen entre procesos correctivos y compensatorios pueden ser más proclives a reconocer un espectro más amplio de legitimados en el segundo proceso. ${ }^{35}$ Sería el caso de la Unión Europea, cuya Directiva $2014 / \mathrm{IO}_{4},{ }^{36}$ relativa a las acciones de dańos por infracciones a la libre competencia, reconoce legitimación activa a los agentes económicos situados en todos los niveles de la cadena de suministro.

Siguiendo esta lógica, dado que el régimen procesal chileno es similar al europeo en cuanto a la separación de los procesos de interés público y privado en libre competencia, pensamos que un comprador indirecto solo gozaría de legitimación activa en el primero si logra acreditar que se vio afectado por dicho traspaso o pass on.

Otro problema de legitimación viene dado por los consumidores que no pudieron comprar en razón de un alza de precio anticompetitiva. Sus bolsillos no se vieron afectados, pero sí sus opciones de compra del producto. ¿Gozan de legitimación activa en el proceso de interés público? En Chile no habría inconveniente para ese propósito, en la medida que se logre acreditar un nexo causal entre el encarecimiento del producto y el desistimiento de compra.

Está también el caso de los consumidores que se ven impedidos de acceder a bienes sustitutos producto del bloqueo de innovaciones de un competidor a otro. En este caso, la oferta del producto tradicional y su precio permanecen intactos, solo que los consumidores han perdido la posibilidad de acceder a otros productos o a mejores precios. ¿Tendrían legitimación para accionar? Claro que sí, sin perjuicio de las dificultades que deberán enfrentar para acreditar una afectación real de sus intereses. La razón es que el beneficio impedido por la conducta anticompetitiva, medido conforme al test de causalidad «but-for» o "de no ser pon», podría consistir en meras conjeturas. Así, en un caso sobre bloqueo de innovación tecnológica, una corte estadounidense declaró que "sería enteramente especulativo y más allá de la competencia de un procedimiento judicial crear a posteriori un universo tecnológico que nunca existió [...] o determinar los beneficios y detrimentos que los productos no-Microsoft hubieran traido al mercado». ${ }^{37}$

35 Crane, Daniel, cit. (n. 32), pp. 682 ss.

${ }_{36}$ Directiva 20I4/IO4/UE del Parlamento Europeo y del Consejo del 26 de noviembre de 20I4, relativa a determinadas normas por las que se rigen las acciones por daños en virtud del derecho nacional, por infracciones del derecho de la competencia de los Estados miembros y de la Unión Europea. Diario Oficial de la Unión Europea. 5 de diciembre de 2014. L 349/I.

${ }_{37}$ Moth con Microsoft, 444 F.3d 3I2, 324 (4th Cir. 2006) (citando In re Microsoft, I27 
Por lo mismo, autores como Hovenkamp han sostenido que, atendida la mayor dificultad de los particulares para acreditar su legitimación activa en casos de bloqueo anticompetitivo de innovación, este debería ser el principal foco de atención de las autoridades de libre competencia que están eximidas de esa carga probatoria. ${ }^{8}$ Sobre todo porque "el daño económico causado a las restricciones de innovación puede ser enorme, tal vez mayor que aquellos causados por restricciones tradicionales sobre precio u oferta»..$^{39}$

¿Y si se trata de consumidores que se vieron beneficiados por una guerra de precios? Pensamos que, en este caso, gozarían igualmente de legitimación activa, dado que su interés legítimo estriba en la eventual restricción ilegal a la competencia que suele suceder a semejante exterminio comercial.

En materia de competidores, está el dilema de aquellos que no formaron parte del cartel pero se vieron beneficiados por el alza de precios. ¿Pueden ser considerados como «afectados» para efectos de legitimación activa? Nuestra respuesta es que «depende» de si logran acreditar un perjuicio distinto al precio por el que pudo cobrar sus productos. Por ejemplo, daño reputacional por el solo hecho de realizar la misma actividad empresarial de los coludidos.

\section{LA REPRESENTACIÓN JUDICIAL Y LA LEGITIMACIÓN ACTIVA EXTRAORDINARIA DE CUERPOS INTERMEDIOS EN PROCESOS SANCIONATORIOS DE LIBRE COMPETENCIA}

En teoría, un cuerpo intermedio podría interponer la acción de libre competencia en procesos de interés público bajo tres calidades diferentes: a) como representante de consumidores legitimados individualmente; b) como legitimado activo extraordinario por ser consumidor $u$ oferente en el mercado concernido; y c) como legitimado activo titular de un interés colectivo o difuso eventualmente lesionado por una conducta anticompetitiva.

La primera figura no admite mayores problemas, pues descansa en el instituto de la representación o mandato procesal, en virtud del cual un sujeto actúa por otro en juicio. Obedece a un presupuesto del proceso y no de la acción. Como explica Romero Seguel, a través de la representación

\section{F. Supp. 2d 702, 7II (200I).}

${ }^{38}$ Hovenkamp, Herbert, The Obama administration and section 2 of the Sherman Act, en Boston University Law Review 90 (2010), pp. I.616-1.617.

39 Hovenkamp, Herbert, cit. (n. 38), p. I.617. 
de la parte en el proceso «se produce en el representado un determinado efecto jurídico, como puede ser celebrar un contrato, deducir una demanda o contestarla, reconvenir, suscribir una transacción, etcétera»..$^{40}$

Esta figura no requiere autorización legal porque se deriva de las disposiciones del derecho común civilit ${ }^{41}$ procesal. ${ }^{42}$ En este caso, los sujetos legitimados en el juicio son los asociados representados individualmente por el ente asociativo y no el ente mismo.

Esta representación es ejercida, por ejemplo, por las asociaciones de consumidores según lo reconoce la Ley 19.496, de protección al consumidor, en su artículo 8: «d) Representar a sus miembros y ejercer las acciones a que se refiere esta ley en defensa de aquellos consumidores que le otorguen el respectivo mandato; e) representar [...] el interés individual [...] de los consumidores ante las autoridades jurisdiccionales o administrativas».

La segunda modalidad es también relativamente pacífica, pues corresponde a la legitimación extraordinaria que, como vimos, la legislación y la jurisprudencia nacional sobre libre competencia reconocen a cualquier sujeto particular que se ha visto afectado por conductas anticompetitivas en un mercado.

La tercera calidad, en cambio, corresponde a una hipótesis sustantiva de legitimación supraindividual. Se refiere a la posibilidad de que un cuerpo intermedio ejerza una acción en nombre propio, como titular de un interés colectivo o difuso, para obtener la protección del interés público en la libre competencia.

Al respecto, es preciso distinguir, en primer lugar, entre interés colectivo y difuso. Si bien ambos intereses son de carácter supraindividual, cuya titularidad corresponde a un grupo, cuerpo asociativo o comunidad, difieren en cuanto a la vinculación entre los miembros de ese conjunto.

\section{Una distinción necesaria entre interés colectivo y difuso}

En los intereses difusos, la vinculación se da en torno a un hecho que afecta de modo semejante a varias personas, mientras que el interés colectivo supone una vinculación previa, de carácter jurídico, entre los afectados. Es así como Aguirrezabal Grünstein, siguiendo a Pellegrini

${ }^{40}$ Romero Seguel, Alejandro, Curso de derecho procesal civil, Los presupuestos procesales relativos al órgano jurisdiccional y a las partes (2. a edición, Santiago, Thomson Reuters, 20I4) II, p. 319.

${ }^{41}$ Artículo I448 del Código Civil.

${ }^{42}$ Artículo 4 ss. del Código de Procedimiento Civil. 
Grinover, ${ }^{43}$ De Camargo Mancuso ${ }^{44}$ y Barrios de Angelis, ${ }^{45}$ define intereses difusos como «aquellos intereses supraindividuales de naturaleza indivisible de los que son titulares sujetos indeterminados unidos por circunstancias de hecho», ${ }^{46}$ y a los colectivos como aquellos que "también son de naturaleza supraindividual e indivisible, pero entre los titulares de esos intereses existe algún tipo de vinculación jurídica». ${ }^{47}$ Ahondando en esta distinción, esta autora nacional explica que «los intereses difusos se refieren al sujeto no como individuo sino como miembro de un grupo que puede ser más o menos amplio, pero indeterminado o de muy difícil determinación, mientras que los intereses colectivos atañen a grupos delimitados en que los miembros se encuentran determinados o son fácilmente determinables»..$^{8}$

De acuerdo con esta distinción, podemos sostener entonces que, si bien el interés supraindividual sustentado por una asociación puede ser colectivo o difuso, solo es colectivo cuando es invocado en relación con sus asociados, pues obedece al interés común de sujetos unidos por un vínculo jurídico con ese cuerpo intermedio. En este sentido, Giannini explica que los intereses colectivos son aquellos cuyo portador o centro de referencia corresponde siempre «a un ente exponencial de un grupo no ocasional».49

La distinción anterior es recogida también por el legislador chileno. La Ley 19.496 establece que: «Se considerarán de interés colectivo a las acciones que se promueven en defensa de derechos comunes a un conjunto determinado o determinable de consumidores, ligados con un proveedor por un vinculo contractual. Son de interés difuso las acciones que se promueven en defensa de un conjunto indeterminado de consumidores afectados en sus derechos».5०

${ }_{43}$ Pellegrini Grinover, Ada, A problemática dos interesses difusos, en Pellegrini Grinover, Ada (editora), A tutela dos interesses difusos (Sao Paulo, Max Limonad, 1984), pp. $19-45$.

${ }^{44}$ De Camargo Mancuso, Rodolfo, Comentários ao código de proteção do consumidor (São Paulo, Saraiva, I99i).

45 Barrios De Angelis, Dante, Introducción al estudio del proceso. La psicología y la sociología del proceso, El Ombudsman, La defensa de los intereses difusos (Buenos Aires, Depalma, 1983), p. I26.

${ }^{46}$ Aguirrezabal Grünstein, Maite, Algunas precisiones en torno a los intereses supraindividuales (colectivos y difusos), en Revista Chilena de Derecho 33 (2006) I, p. 75.

47 Aguirrezabal Grünstein, Maite, Algunas precisiones, cit. (n. 46), p. 75.

${ }^{48}$ Aguirrezabal Grünstein, Maite, Algunas precisiones, cit. (n. 46), p. 84.

49 Giannini, M.S., La tutela degli interessi collettivi nei procedimenti amministrativi, en A.A.V.V., Le azioni a tutela degli interessi collettivi (Padova, Padova, 1976), p. 23.

so Artículo 50, inciso quinto. El énfasis en texto espaciado es nuestro. 
Conforme a esta distinción, el interés invocado por el cuerpo intermedio será colectivo si se refiere al del conjunto de sus integrantes, y difuso si versa sobre una categoría de sujetos no vinculados jurídicamente entre sí.

\section{Los cuerpos intermedios que no son oferentes o consumidores del mercado concernido carecen de legitimación activa extraordinaria}

Siguiendo a la legislación y jurisprudencia nacional y extranjera, un cuerpo intermedio que no es agente económico — oferente o demandantedel mercado en el que incide una supuesta conducta anticompetitiva carece de legitimación activa por falta de afectación de sus intereses. Y si lo esgrimido fuera el interés colectivo de sus miembros o un interés difuso que dice representar según sus estatutos, la afectación solo sería indirecta o doblemente extraordinaria o excepcional. Se ubicaría, por así decirlo, en un tercer círculo concéntrico de sujetos legitimados para accionar en nombre propio por un interés público, solo después de los directamente afectados: el titular del interés público objeto del proceso y los oferentes o consumidores del mercado relevante.

Esta excepcionalidad adicional es la que llevó al TDLC a declarar que una asociación de consumidores «no tiene la calidad de sujeto pasivo inmediato que participa actual o potencialmente en los mercados, por lo que, en principio, carecería de un interés legítimo para accionar en esta sede. No tendría lo que en doctrina se denomina legitimación activa ordinaria para actuar, esto es, aquella que le corresponde al titular de la situación jurídica sustancial que se deduce en juicio». .I Hacemos la salvedad, sin embargo, que debió decir legitimación activa "extraordinaria», pues cuando el objeto del proceso es la protección de un interés público, el único legitimado activo ordinario es la sociedad en su conjunto; los demás solo podrían ser legitimados extraordinarios. Con todo, la conclusión permanece, pues semejante asociación carecería tanto de legitimación ordinaria como extraordinaria.

Un criterio similar rige en Estados Unidos. En el caso Maryland Highways Contractors Ass'n con Maryland, ${ }^{52}$ la Corte de Apelaciones del cuarto distrito rechazó la legitimación activa en libre competencia de una asociación de empresas constructoras de obra pública en atención a que carecía de afectación propia como ente asociativo. La asociación había alegado que el ilícito anticompetitivo no había afectado sus bienes o situación eco-

${ }_{51}$ TDLC, sentencia rol $146 / 2015$, considerando decimosegundo. El mismo fallo indica que esta última definición de legitimación activa corresponde a Romero SEguel.

${ }_{52}$ Maryland Highways Contractors Association, Inc con Maryland, 933 F2d I246, I252-53 (4th Cir 199I). 
nómica, pero sí su «propósito organizacional». Sin embargo, la Corte rechazó este argumento citando al efecto un precedente de la Corte Suprema de Estados Unidos, según el cual «el interés organizacional abstracto con un asunto que podría ser afectado por una decisión judicial no sustituye la lesión concreta exigida por el Articulo III. En la medida que estas organizaciones busquen legitimación basada en sus intereses especiales (en el asunto materia de litigación) su acción debe fracasar. Desde que ellas no alegan ningún daño a ellas mismas como organizaciones, [...] ellas pueden establecer legitimación unicamente como "representantes de aquellos miembros que han sido dañados efectivamente", y asi podrian presentar acciones en su derecho propio».53

Asimismo, otra Corte rechazó la demanda de una asociación de corredores inmobiliarios en dicho mercado por falta de legitimación activa. ${ }^{54} \mathrm{La}$ asociación había alegado la afectación de su actividad "conexa» de prestar servicios de información a los proveedores. La sentencia estimó que el mercado relevante afectado era el inmobiliario y no el conexo de información, razón por la cual la asociación no participaba en el mercado. Además, las prácticas anticompetitivas del demandado no se dirigían a la asociación como agente económico sino que a sus miembros, lo que hacía que la eventual afectación de su interés fuese meramente indirecta e incidental.

Otra causal de rechazo de la legitimación activa de cuerpos intermedios en esta jurisdicción es la mayor afectación del interés individual de sus miembros vis-à-vis el interés de la asociación. En el caso Associated General Contractors, la Corte Suprema federal rechazó la legitimación activa de una asociación de multiempleadores en atención a que «la existencia de una clase identificable de personas cuyo autointerés los motivaría normalmente a vindicar el interés público en el cumplimiento de la libre competencia disminuye la justificación para permitir a una parte más remota [...] ejercer el oficio de un fiscal general privado».55

Observamos una realidad parecida en el derecho comunitario europeo sobre asociación de consumidores, que carecen de legitimación activa colectiva a menos que hayan sido "habilitadas" por el Estado respectivo. Al respecto, en el caso Unión de Pequeños Constructores con Consejo, el Tribunal de Justicia de la Unión Europea confirmó el criterio de que

53 Simon con Eastern Kentucky Welfare Rights Org., 426 U.S. 26, 40, 96 S.Ct. 1917, 1925, 48 L.Ed.2d 450 (1976). Ver también el fallo de la misma Corte en Sierra Club con Morton, 405 U.S. 727, 739, 92 S.Ct. I36I, I368, 31 L.Ed.2d 636 (1972).

${ }_{54}$ S. W. Suburban Bd. con Beverly Area Plan 830 F.2d 1374 (7th Cir. 1987).

ss Associated General Contractors, 459 U.S. at 542, I03 S.Ct. at 910. Ver también S.W. Suburban Bd. con Beverly Area Plan 830 F.2d 1374 (7th Cir. 1987). 
una asociación solo podría comparecer en juicio bajo tres calidades: a) representante de empresas individuales; b) sujeto directamente afectado en su posición negociadora; o c) «en las situaciones en que una disposición legal reconoce expresamente a las asociaciones profesionales una serie de facultades en el marco del procedimiento»..$^{56}$ En consecuencia, en ausencia de representados individuales o afectación de sus propios negocios, la asociación solo podría accionar para proteger la libre competencia si la ley así lo permite.

De ahí también las definiciones que adopta la reciente Directiva 2020/1828, relativa a las acciones de representación para la protección de los intereses colectivos de los consumidores. ${ }^{57}$ Define «entidad habilitada» como «toda organización u organismo público que represente los intereses de los consumidores, que haya sido designado como tal por un Estado miembro para el ejercicio de acciones de representación de conformidad con la presente Directiva»; $5^{8} \mathrm{y}$ "acción de representación" como "toda acción para la protección de los intereses colectivos de los consumidores ejercitada por una entidad habilitada como parte demandante en nombre de los consumidores por la que se solicite una medida de cesación o una medida resarcitoria, o ambasm.99

A nivel de países, esta habilitación puede ser verificada, por ejemplo, en el caso del Reino Unido. Hasta 2013, con excepción de un ente certificado por el gobierno, las asociaciones de comerciantes o consumidores carecían de legitimación activa colectiva o difusa para la protección del interés público en la libre competencia. ${ }^{60}$ Asimismo, en Francia, como explica SÁNCHEZ, «de entrada ninguna ley habilita con carácter general a las asociaciones para actuar en defensa de este tipo de intereses [colectivos], lo que la doctrina francesa lo justifica en atención a que estamos en una parcela del interés general». ${ }^{\mathrm{I}}$

${ }_{56}$ Tribunal de Justicia de la Unión Europea, Caso 500/oo, sentencia del 25 de julio de 2002, apartado 8.

57 Directiva (UE) 2020/1828 del Parlamento Europeo y del Consejo, del 25 de noviembre de 2020. Diario Oficial de la Unión Europea, 4 de diciembre de 2020.

${ }_{58}$ Artículo 3 (4). El énfasis en texto espaciado es nuestro.

59 Artículo 5 (5). El El énfasis en texto espaciado es nuestro.

6o Department for Business, Innovation \& Skills, Private Actions in Competition Law: A Consultation on options for reform (2012), p. 27.

${ }^{6 r}$ SÁnchez, Ricardo Juan, La legitimación en el proceso civil (Pamplona, Thomson Reuters, Aranzadi, 20I4), p. I83. 
3. Los cuerpos intermedios externos al mercado concernido pueden gozar de legitimación activa extraordinaria si el legislador asi lo establece

Ahora bien, la falta de legitimación colectiva o difusa de los cuerpos intermedios en libre competencia no obsta a que el legislador pueda reconocerla de modo expreso.

Por ejemplo, el gobierno británico publicó, en 2013, un documento titulado Private Actions in competition Law. A consultation on options for reform - government response, ${ }^{62}$ que anunció la posibilidad de proteger la libre competencia mediante acciones supraindividuales. Para evitar abusos o demandas temerarias, el documento advierte que «solo serán autorizadas para ser presentadas por afectados o por representantes de los afectados, como las asociaciones de comerciantes o consumidores». ${ }^{63}$ Estas acciones pueden ser simplemente de cesación o cumplimiento forzado del ordenamiento legal (enforcement o injunctive relief), o de indemnización de perjuicios (redress). Este anuncio fue concretado en The Consumer Rights Act 20I5, que introdujo modificaciones a The Competition Act 1998 relativas a la legitimación activa por intereses colectivos o difusos en libre competencia.

En Chile, las asociaciones de consumidores gozaron de legitimación colectiva y difusa en libre competencia recién a partir de 2004, precisamente, porque así lo dispuso una reforma a la Ley 19.496 introducida ese ańo por la Ley 19.955, que dispuso en su artículo 8 que "las organizaciones a que se refiere el presente párrafo podrán realizar las siguientes actividades: e) representar [...] el interés colectivo y difuso de los consumidores ante las autoridades jurisdiccionales o administrativas, mediante el ejercicio de las acciones y recursos que procedan».

La historia de este precepto dejó constancia expresa de que las asociaciones de consumidores pueden accionar en defensa de intereses colectivos o difusos solo porque la ley así lo permite. Se enfatiza que, para evitar abusos procesales, este tipo de procedimientos debe contener «una serie de resguardos, como definir de manera taxativa los legitimados activos», ${ }^{64}$ en otras palabras «se restringe la legitimidad activa para iniciar el procedimiento a cuatro actores». ${ }^{65}$

${ }_{62}$ Department for Business, Innovation \& Skills, Private Actions in Competition Law. A consultation on options for reform - government response (2013).

${ }_{63}$ Department for Business, Innovation \& Skills, cit. (n. 62), p. 6.

${ }^{64}$ Mensaje presidencial que dio inicio a la tramitación del Proyecto de Ley que culminó en el dictamen de la Ley 19.955, que modifica la Ley 19.955, de reforma a la Ley 19.496. Biblioteca del Congreso Nacional de Chile, Historia de la Ley I9.955. Sobre protección de los derechos de los consumidores, p. 4.

6s Biblioteca del Congreso Nacional de Chile, cit. (n. 64), p. 90. 
En igual sentido, el TDLC y la Corte Suprema ${ }^{66}$ han declarado que estas asociaciones gozan de legitimación extraordinaria en libre competencia porque así lo reconoce la ley expresamente, citando al efecto el artículo 8 de la Ley 19.496. El TDLC incluye a estas asociaciones entre «aquellos que en virtud de una ley pueden ejercer la acción en nombre de dichos agentes económicos. Vale decir, también aquellos que pueden tener una legitimidad activa extraordinaria». ${ }^{67}$. La Corte, por su parte, ha sostenido que «se le reconoce a Conadecus —en su condición de Asociación de Consumidoreslegitimación activa extraordinaria, puesto que la tutela que puede solicitar no está referida a derechos propios, y esta posibilidad de actuación les viene atribuida por ley expresa». ${ }^{68}$

En consecuencia, de acuerdo con estos criterios legales y jurisprudenciales, un cuerpo asociativo goza de legitimación activa extraordinaria como titular de un interés colectivo o difuso afectado por conductas anticompetitivas en la medida que el legislador así lo prevea. A falta de habilitación legal, la entidad carecería de legitimación activa, incluso aunque se le haya reconocido la calidad de interesada en procedimientos no contenciosos. Como se sabe, «el interés legitimo que exige el DL 211 para actuar en uno u otro procedimiento es diferente, siendo más restrictiva la exigencia para participar en un procedimiento contencioso». ${ }^{69}$

En otras palabras, todo silencio legislativo en materia de legitimación colectiva o difusa en libre competencia significa falta de habilitación para accionar. Hasta ahora, el legislador ha omitido conceder esta legitimación especial a los cuerpos asociativos con excepción de los consumidores. La jurisprudencia del TDLC ha guardado coherencia con este criterio, incluso cuando ha reconocido esta prerrogativa a asociaciones de oferentes o proveedores, pues lo ha hecho en razón de su interés colectivo o difuso en el consumo de un producto. ${ }^{70}$

\section{La confusión entre legitimación activa colectiva y representación procesal en la jurisprudencia nacional sobre asociaciones de agentes económicos}

Sin perjuicio de lo anterior, a la hora de pronunciarse sobre la legitimación colectiva de las asociaciones de consumidores, tanto el TDLC como la

${ }^{66}$ Corte Suprema, sentencia rol II.363-2015, considerando quinto.

${ }_{67}$ TDLC, sentencia rol I46/2015, considerando decimotercero.

${ }^{68}$ Corte Suprema, sentencia rol II.363-20I5, considerando quinto.

${ }_{69}$ TDLC, sentencia rol 146/2015, considerando vigésimo.

70 Cfr. TDLC, causas contenciosas roles 64-05, 67-05, II3-06. Solo tenemos registro de un reconocimiento implícito de legitimación de asociación de oferentes en causa rol 26-04. 
Corte Suprema han tendido a confundir dos institutos procesales diferentes: la representación en juicio y la legitimación activa. En efecto, estos tribunales reconocen que estos entes gozan de legitimación activa porque "pueden ejercer la acción en nombre de dichos agentes económicos», ${ }^{7 \mathrm{~T}} \mathrm{O}$ "puesto que la tutela que puede solicitar no está referida a derechos propios»..$^{72}$ Sin embargo, a menos que sea en sentido figurado, el ejercicio de la acción en "nombre de otro» o aquella que "no está referida a derechos propios» no pueden ser interpretados como hipótesis de legitimación activa, sino de representación procesal.

Esta confusión se produce, principalmente, porque el interés supraindividual de una asociación continúa siendo imputado a una pluralidad de individualidades en vez de a la asociación misma, como debería ser. La titularidad de un interés grupal o conjuntivo solo puede pertenecer al cuerpo asociativo y no a los individuos. Por tanto, cuando la asociación acciona en interés supraindividual, está incurriendo en una hipótesis de legitimación activa en nombre propio y no como representante de un interés ajeno.

Este problema es bien explicado por Aguirrezabal Grünstein, para quien «suele confundirse la legitimación colectiva con situaciones de representación», ${ }^{73}$ debido al desafío dogmático que la protección de intereses supraindividuales plantea a los moldes clásicos del derecho procesal. Como este último solo reconoce la titularidad de intereses individuales o públicos, se ve forzado a calificar erróneamente la acción de interés colectivo como representación de terceros, en circunstancias que corresponde a una hipótesis de legitimación activa supraindividual en nombre de la asociación como titular de dicho interés.

Para no incurrir en este error, es preciso, como explica Bujosa VAdell: «recurrir a nuevos conceptos, estructuras y mecanismos para la defensa de los intereses que conciernen a enteras categorías o grupos de personas, superando los propios de una concepción tradicional del proceso; $\mathrm{y}$, entre ellos, el de la vieja concepción, excesivamente restrictiva e individualista de la legitimación para demandar». ${ }^{74}$

${ }^{71}$ Ibid., considerando decimotercero.

${ }_{72}$ Corte Suprema, sentencia rol II.363-20I5, considerando quinto.

73 Aguirrezabal Grünstein, Maite, Capacidad y legitimación del grupo de afectados en la ley de protección al consumidor, en Revista Chilena de Derecho Privado 31 (2018) diciembre, p. 368.

${ }^{74}$ Bujosa Vadell, Lorenzo, Artículo II. Legitimación para la defensa de derechos e intereses de consumidores y usuarios, en Gómez de LiaÑo GonZÁlez, Fernando (coordinador), La Ley de Enjuiciamiento Civil (Oviedo, Forum, 200o), p. 75. 
La solución pasa, entonces, por reconocer que se trata de un asunto de legitimación sustantiva y no de representación procesal o, a lo más, uno de representación adecuada que coincide con la de legitimación, según AguiRREZABAL GrüNSTEIN, «en el sentido de que el representante es parte en el proceso por tener una posición determinada frente al objeto litigioso y un interés en el mismo». ${ }^{75}$ Es lo que se conoce también como legitimación ideológica o asociativa, «que porta el interés colectivo, de grupo o de clase, y que se funda en la necesidad de superación del garantismo individualista y de nacimiento de un nuevo tipo, social o colectivo, concebido como salvaguardia, no solo del individuo en un proceso individualista, sino de los nuevos grupos y cuerpos intermedios». ${ }^{76}$

De lo dicho se desprende que la única hipótesis de legitimación supraindividual de estas entidades supone la titularidad del interés colectivo de sus miembros o difuso de un grupo de similares características, el cual no pertenece a ninguno de ellos individualmente, sino a todos ellos constituidos como asociación o categoría.

La historia de la Ley 19.955 dejó constancia expresa de este propósito: «el proyecto incorpora la defensa de los intereses colectivos y difusos de los consumidores, institución que simplificará significativamente la solución de problemas que afectan intereses supraindividuales [...] Tal protección viene a dar respuesta a la necesidad de articular herramientas procesales adecuadas que permitan poner en práctica instituciones sustantivas». ${ }^{77}$ AgUIRREZABAL GRÜNSTEIN confirma este aserto al sostener que la letra e) del artículo 8 se refiere a una hipótesis de representatividad adecuada o de legitimación y no de representación procesal, «lo que quiere decir fundamentalmente que la asociación será la parte en el proceso con todas las consecuencias que ello conlleva». ${ }^{78}$

\section{LA LEGITIMACIÓN ACTIVA EXTRAORDINARIA EXIGE QUE EL INTERÉS COLECTIVO INVOCADO SEA, ADEMÁS, LEGÍTIMO AD CAUSAM}

Como vimos, la jurisprudencia nacional de libre competencia señala que la legitimación activa no depende únicamente de la habilitación legal extraordinaria para demandar a nombre propio en defensa de un interés público, sino también de que el interés esgrimido como factor habilitante sea legítimo en el caso concreto. En el caso de intereses colectivos o difusos,

75 Aguirrezabal Grünstein, Maite, Capacidad y legitimación, cit. (n. 73), pp. 368 y 369.

$7^{76}$ Aguirrezabal Grünstein, Maite, Capacidad y legitimación, cit. (n. 73), p. 369.

77 Biblioteca del Congreso Nacional de Chile, cit. (n. 64), p. 5.

${ }^{78}$ Aguirrezabal Grünstein, cit. (n. 73), pp. 370, nota al pie iI. 
a los requisitos ya enunciados de a) afectación directa o indirecta por las conductas denunciadas, cabe añadir que el interés debe ser b) suficientemente representativo, c) exento de conflictos de interés, y d) acreditable y protegible sin la participación individual de los afectados directos.

\section{Interés colectivo suficientemente afectado}

La jurisprudencia ha sido clara en sostener que la legitimación activa depende también de la afectación real del interés asociativo. En otras palabras, no bastaría con invocar el reconocimiento legislativo a la posibilidad de accionar. Por ejemplo, en relación con la afectación del interés colectivo o difuso de los consumidores, el TDLC declaró, en su sentencia I46, que es preciso determinar, además, si ellos «tienen esa calidad de sujeto pasivo inmediato de las conductas denunciadas en autoss. ${ }^{79}$

Es interesante esta sentencia porque, si bien el TDLC y la Corte Suprema coincidieron en que Conadecus gozaba de reconocimiento legal para accionar, discreparon en cuanto a la legitimidad del interés invocado. El TDLC declaró que esta asociación carecía de un interés legitimante debido a que el ilícito de acaparamiento solo había afectado a los competidores de las empresas denunciadas y no a los consumidores: «a diferencia de otras conductas contrarias a la libre competencia — como los carteles sobre precios y otras condiciones comerciales o los abusos explotativos-en las que generalmente los afectados directos son los consumidores, en los actos exclusorios, como el acaparamiento, los afectados directos son los competidores actuales o potenciales del acaparadon.${ }^{80}$ Sin embargo, la Corte Suprema revirtió esta decisión "por estimar que la participación de determinadas empresas de telefonía móvil en un concurso de asignación de espectro radioeléctrico, reviste un potencial efecto anticompetitivo que puede alcanzar a quienes, como consumidores, requieren dichos servicios». ${ }^{8 \mathrm{I}}$

Más adelante, confirmando que el interés legítimo depende del tipo de conducta imputada, el Tribunal reconoció legitimación activa extraordinaria a Conadecus en un caso sobre incumplimiento de medidas y de avenimiento, en atención a que «i) existe un interés de los consumidores involucrado en el presente caso; ii) que Conadecus es una asociación de consumidores; y iii) que, en cuanto tal, puede representar legitimamente el antedicho interés, pues la ley le confiere expresamente legitimación activa extraordinaria». ${ }^{82}$

79 TDLC, sentencia rol I46/20I5, considerando decimoquinto.

8o Ibid., considerando decimoctavo.

${ }^{81}$ Corte Suprema, sentencia rol II.363-2015, considerando octavo. Ver también considerando noveno.

${ }^{82}$ TDLC, sentencia rol 159/20I7, considerando noveno. 
Asimismo, en Estados Unidos, una asociación de agentes económicos goza de legitimación colectiva si logra acreditar que el daño sufrido es «del tipo que las leyes de libre competencia fueron diseñadas para evitarn. ${ }^{83}$ De hecho, «sería anómalo [...] interpretar la Ley Clayton como para autorizar a un demandante particular para asegurar una medida en contra de una amenaza de lesión para la cual el no estuviera legitimado para pedir compensación si la lesión se concretara». ${ }^{84}$

Otro factor legitimante en esta materia es el tiempo transcurrido desde la constitución de la asociación. Por ejemplo, la ley de protección al consumidor habilita a las asociaciones de consumidores para accionar en nombre del interés colectivo o difuso cuando haya estado constituida «a lo menos, con seis meses de anterioridad a la presentación de la acción». ${ }^{85}$ Esta exigencia se ordena, naturalmente, a asegurar una afectación real del interés invocado.

\section{Interés colectivo o difuso debidamente representado}

Dado que la sentencia dictada en un juicio de interés supraindividual afectará a todos los integrantes de un grupo o categoría, el interés invocado debe ser, además, suficientemente figurativo del interés común en el caso concreto. Para tal efecto, las jurisdicciones han aplicado distintos criterios de representatividad o de adhesión a la pretensión judicial.

En el caso de las asociaciones de consumidores en Chile, por ejemplo, el ejercicio de la acción exige la autorización del directorio de la asociación. ${ }^{86}$

La legislación de libre competencia del Reino Unido, en cambio, exige que la legitimación activa colectiva o difusa sea aprobada previamente por el Competition Appeal Tribunal mediante una "orden de proceso colectivo» (collective proceeding order $o C P O),{ }^{87}$ la cual exige, como primer requisito, que «la persona que inició el procedimiento colectivo sea una persona que, si la orden fuere dada, el Tribunal podría autorizarla a actuar como representante en esos procedimientos de acuerdo con la subsección $81{ }^{88}$ Esta subsección, por

${ }^{83}$ S. W. Suburban Bd. con Beverly Area Plan 830 F.2d 1374 (7th Cir. 1987), que aplica los criterios generales de la Corte Suprema de Estados Unidos en los casos Brunswick Corp. con Pueblo Bowl-O-Mat, Inc., 429 U.S. 477 y Cargill, Inc. con Monfort of Colorado, Inc. U.S. Dec 9, 1986, 479 U.S. 104 (1986)

${ }^{84}$ Ibid.

${ }^{85}$ Artículo 5I, número I, letra b) de la Ley 19.496.

${ }^{86}$ Ibid.

${ }^{87}$ Hacemos la salvedad de que, en derecho británico, la distinción entre interés colectivo y difuso, valga la redundancia, es más bien difusa, dado que el primero suele incluir también al segundo.

${ }^{88}$ The Competition Act 1998, Section 47 B 5) a): "The person who brought the pro- 
su parte, establece que una persona que no sea sujeto afectado podría gozar de la representatividad adecuada del interés colectivo «solo si el tribunal considera que es justo y razonable para esa persona actuar como representante en esos procedimientos». ${ }^{89}$

A su vez, los modelos de legitimación activa en libre competencia basada en intereses difusos han introducido mecanismos procesales de entrada o salida individual de una categoría, conocidos como opt-in y opt-out, para efectos de oponibilidad o inoponibilidad de la sentencia, respectivamente. Por ejemplo, los regímenes de opt-in y de opt-out se distribuyen de modo parejo entre los países europeos..$^{\circ \circ}$ En Estados Unidos, en cambio, la regla general es el régimen de opt-out, lo que significa que los miembros de una clase se entienden pertenecer a ella a menos que opten por dejarla formalmente. ${ }^{9}$

\section{Interés cuya afectación puede ser acreditada y remediada en el proceso} sin la participación individual de los afectados directos

Otro factor de legitimidad de un interés supraindividual es que el juicio no requerirá la participación de los afectados directos en la etapa de prueba o de ejecución del fallo, debido a que el ilícito causó un impacto genérico y uniforme en ellos. En Estados Unidos, por ejemplo, la Asociación Nacional de Vendedores de Máquinas de Oficina fue reconocida como legitimada activa para demandar por prácticas anticompetitivas, precisamente, porque «la acción ataca una presunta política del demandado igualmente aplicable e igualmente perjudicial para todos los miembros de Nomda y la medida buscada es equitativa». ${ }^{22}$ Parafraseando un caso de legitimación general, ${ }^{93}$ la sentencia terminó resumiendo este requisito de modo magistral: una asociación goza de esta legitimación cuando su única petición «es tan efectiva como Ioo, y, concomitantemente, [...] Ioo medidas no son más eficaces que una». ${ }^{94}$

ceedings is a person who, if the order were made, the Tribunal could authorise to act as the representative in those proceedings in accordance with subsection 8 ".

${ }^{89}$ Ibid., Section 47B 8) b): «Only if the Tribunal considers that it is just and reasonable for that person to act as a representative in those proceedings».

$9^{\circ}$ Cfr. Nagy Csongor, István, Collective actions in Europe. A comparative, economic and transsystemic analysis (Berlín, Springer, 2019) pp. 7I-II2.

${ }_{91}$ Federal Rule of Civil Procedure 23 c) 2) B) y 23 d) 4).

${ }_{92}$ National Office, Etc. con Monroe, the Calculator Co. 484 F. Supp. 1306 (N.D. Ill. 1980): "The complaint attacks an alleged policy of defendant equally applicable and equally detrimental to all NOMDA members and the relief sought is equitable».

${ }_{93}$ Sierra Club con Morton, 405 U.S. 727 (1972) 92 S. Ct. I36I.

94 "One injunction is as effective as I0o, and, concomitantly, [...] Ioo injunctions are no more effective than one». 
En cambio, este requisito se entiende incumplido en aquellos casos donde, para acoger la demanda, es necesario probar conductas del demandado dirigidas a individuos específicos de la asociación. Sirve aquí el citado caso Suburban, ${ }^{95}$ en que una corte de distrito, siguiendo un precedente de la Corte Suprema federal estadounidense, ${ }^{96}$ negó legitimación activa a una asociación de corredores inmobiliarios en libre competencia porque, si bien no perseguían una compensación, «la acción aqui no ataca una presunta politica de los demandados igualmente aplicable e igualmente perjudicial para todos los miembros [de la asociación]».97 El fallo sostuvo que la prueba individual era necesaria en razón de que los hechos acusados por la asociación consistían en "boicotear o no realizar negocios con algunos corredores»; «destruir y diluir la reputación y buena voluntad de los corredores en lo referente a sus competencias, profesionalismo y principios éticos»; "haber acosado, amenazado, molestado e intentado intimidar a la demandante y a sus miembros mediante acusaciones falsas de infracción a varias leyes $y$ amenazando con iniciar litigios frivolos en su contra»; $\mathrm{y}$ "haber inducido a vendedores prospectivos de bienes raices en el mercado relevante a infringir sus contratos vigentes con los corredores no preferidos».

Un criterio similar fue aplicado en Association of Independent Gas Station Owners con QuikTrip Corporation, ${ }^{98}$ un caso de predación en que la Corte de Distrito negó legitimación activa a una asociación de dueńos de estaciones de combustible, inter alia, porque el proceso exigía la participación individual de sus miembros. Específicamente, la demanda se sustentaba en hechos individuales que correspondía probar a ellos, como haber sido forzados a vender bajo costo, amenazando así su sobrevivencia en el mercado.

Sin perjuicio de lo anterior, la jurisprudencia norteamericana ha reconocido excepcionalmente la legitimación asociativa en casos que requieren un mínimo de prueba individual. Por ejemplo, aquella necesaria para acreditar la sincronía de las transacciones en un caso de discriminación de precios donde los agentes de mercado enfrentan circunstancias idénticas. ${ }^{99}$

Una segunda orientación en esta materia viene dada por la aptitud de la demanda para satisfacer las pretensiones de todos los asociados de modo

95 Southwest Suburban Bd. con Berverly Area Plan, 830 F.2d at 1380-8I.

${ }_{96}^{6}$ Hunt con Washington Apple Advertising Comm'n, U.S. Jun 20, 1977432 U.S. 333 (1977).

${ }_{77}$ Southwest Suburban Bd. con Berverly Area Plan, 830 F.2d at 1380-81: " The complaint here does not attack an alleged policy of defendant[s] equally applicable and equally detrimental to all [SSBR] members».

${ }_{98}$ Case 4:IICV2083 JCH (E.D. Mo. Jul. 20, 2012)

99 NACS, INC. con Cambridge University Press, 990 F. Supp. 245 (S.D.N.Y. 1997). 
uniforme. Al respecto, la ley de libre competencia del Reino Unido establece que las reclamaciones son aptas para un proceso colectivo «solo si el Tribunal considera que ellas levantan asuntos de hecho o de derecho iguales, similares o relacionados y son adecuadas para ser llevadas a un proceso colectivo». ${ }^{100}$

Un tercer parámetro de distinción corresponde a la ausencia de conflictos de interés, dado que impiden calificar la pretensión como compartida o verdaderamente asociativa. Explica Edmonds que en Estados Unidos «un conflicto de interés puede impedir que una organización sea una abogada celosa porque esa organización puede que no persiga la litigación a fondo cuando los intereses de algunos de sus miembros pueden verse dañados por el éxito de la litigación». ${ }^{\text {Ior }}$ Esta afirmación resume las doctrinas sobre legitimación activa asociativa no solo en el campo de la libre competencia, sino en general.

Destacamos, al respecto, algunas frases decidoras de los precedentes norteamericanos: «dado que las asociaciones consisten típicamente en muchos miembros con intereses o visiones sobre cualquier disputa potencialmente en conflicto, existe un peligro de que ciertos miembros de la asociación simpatizarán con la contraparte. En tales casos, no existiría una controversia legitima»; ${ }^{102}$ "no existe "caso o controversia" aqui si contingentes no oficiales de la [organización] son vistos apoyando a ambos lados de la litigación, mientras los cuerpos de gobierno de las instituciones se sientan como espectadores por sobre la "pelea"». ${ }^{\circ 3}$

La jurisprudencia estadounidense sobre libre competencia aplica estos criterios. Como explica la Corte en el caso NACS, INC. con Cambridge University Press, ${ }^{104}$ las sentencias no exigen la aprobación unánime de los integrantes de la asociación para descartar conflictos de interés, pues basta con que la decisión de accionar haya sido adoptada con infracción del proceso decisional interno o que conduzca a un conflicto real o potencial de los intereses de los asociados.

Ejemplo de lo primero es el citado caso Maryland Highways Contractors Association con Maryland, ${ }^{\text {os }}$ en que la Corte rechazó la legitimación activa

${ }_{100}$ The Competition Act 1998, Section 47B 6): "Claims are eligible for inclusion in collective proceedings only if the Tribunal considers that they raise the same, similar or related issues of fact or law and are suitable to be brought in collective proceedings".

ror EDmonds, Nathaniel, Associational Standing for organizations with external conflicts of interest, en The University of Chicago Law Review 169 (2002), pp. 361.

${ }_{102}$ Mountain States Legal Foundation con Dole, 655 F Supp I424, I426 (D Utah 1987).

${ }^{103}$ NCAA con Califano, 622 F2d I382, I39I-92 (ioth Cir 1980).

${ }^{104}$ NACS, INC. con Cambridge University Press, 990 F. Supp. 245 (S.D.N.Y. 1997).

1os Maryland Highways Contractors Association, Inc con Maryland, 933 F2d I246, I25253 (4th Cir 1991). 
de la asociación porque la decisión de litigar había sido adoptada por el Directorio de la Asociación, del que no formaba parte ninguno de los asociados que estaban en desacuerdo o se verían perjudicados por el litigio.

En relación con el segundo criterio de discernimiento, el ejemplo más claro de conflicto de interés es la participación de algunos de los asociados como demandantes y demandados en el juicio. ${ }^{106}$ Sin embargo, el conflicto de interés surge también de pretensiones judiciales que concitan la oposición o el desinterés de algunos de los integrantes del cuerpo asociativo. Por ejemplo, en el caso Associated General Contractors of North Dakota con Otter Tail Power Co., la Corte del Octavo Circuito rechazó la legitimación activa de la asociación debido a la existencia de miembros con distintas disposiciones y situaciones frente a la demanda, lo que hacía preferible su interposición individual y no colectiva. ${ }^{107}$

Sin perjuicio de lo anterior, la jurisprudencia ha admitido la legitimación activa de asociaciones incluso en casos donde existe oposición a la demanda o en que algunos miembros de la asociación se ven beneficiados por las políticas del demandado. Las razones para acceder a ello son principalmente de eficiencia o economía procedimental. Sin embargo, como se señala en NACS, INC. con Cambridge University Press, ${ }^{\text {108 }}$ estos casos corresponden a asociaciones de miles de miembros, donde la unanimidad es prácticamente imposible. De hecho, para proceder de este modo, es necesario que el número de miembros opositores a la acción "parezca ser muy pequeño [...] menos del $I \% » .{ }^{109}$

${ }^{106}$ Southwest Suburban Bd. con Berverly Area Plan, 830 F.2d at 1380-8I.

${ }_{107}$ Associated General Contractors of North Dakota con Otter Tail Power Co., 6II F.2d 684, 691 (8th Cir. 1979): «La acción presentada requiere la participación de los miembros individuales de la asociación. La asociación claramente no está en una posición para hablar por sus miembros sobre la cuestión de si el [acuerdo] infringe las normas de libre competencia. El estatus e intereses de ellos son demasiado diversos y las posibilidades de conflicto demasiado obvias como para hacer de la asociación un vehiculo adecuado para litigar los reclamos de sus miembros. Algunos miembros no están calificados y otros no desean trabajar en el proyecto: algunos apoyan para beneficiarse del trabajo en el proyecto bajo el acuerdo y otros podrían incluso ser dañados al no tener la capacidad de hacerlo. Corresponde a la Corte, y no a los miembros de la asociación, determinar si es que sus intereses requieren representación individual. Aqui, en vista de los conflictos actuales y potenciales, ellos claramente lo requieren». La traducción es nuestra. Ver también S.W. Suburban Bd. con Beverly Area Plan 830 F.2d 1374 (7th Cir. 1987).

${ }_{\text {108 }}$ NACS, INC. con Cambridge University Press, 990 F. Supp. 245 (S.D.N.Y. 1997).
109 Ibid. 


\section{Conclusiones}

De acuerdo con lo expuesto en las secciones anteriores, las conclusiones relevantes de este estudio son las siguientes:

- El proceso correctivo o sancionatorio de libre competencia no tiene por objeto la vulneración de derechos de agentes económicos, sino la afectación del interés público e indisponible de la libre competencia en los mercados.

- En los procesos destinados a la satisfacción de un interés público, la legitimación activa corresponde, por regla general, al titular de ese interés, el cual acciona por medio de su representante. En materia de libre competencia, el titular del interés es la sociedad en su conjunto y su representante es la FNE.

- Sin embargo, la ley también reconoce legitimación activa en libre competencia a sujetos privados. Específicamente, el DL 2II se refiere a ellos como "parte», en contraposición a la FNE (artículo I8, número I), y denomina su acción como "demanda de algún particular» (artículo 20, inciso segundo).

- Esta legitimación no es ordinaria sino extraordinaria, pues la acción se ejerce a nombre propio para la satisfacción de un interés ajeno. Además, por tratarse de una legitimación extraordinaria, su establecimiento solo puede ser por ley y es de derecho estricto.

- El «interés legítimo» exigido al demandante en estos casos no es popular sino cualificado, esto es, la titularidad de la acción está reservada a aquellos que se han visto afectados por la infracción legal. Tratándose de una acción de libre competencia, el afectado debe ser demandante u oferente del mercado concernido.

- Sin embargo, ¿podría una asociación de consumidores u oferentes interponer la acción como titular de un interés colectivo afectado por la conducta anticompetitiva? Siguiendo a la legislación y jurisprudencia nacional y extranjera, la respuesta es no, porque no formaría parte de los sujetos afectados a los cuales el legislador ha reconocido legitimación extraordinaria. Sin embargo, nada obsta a que estas asociaciones puedan gozar de legitimación si el legislador nacional así lo dispone, como sucede en materia de consumidores.

- Sin perjuicio de lo anterior, la legitimación activa no depende únicamente de la habilitación legal extraordinaria para demandar a nombre propio en defensa de un interés ajeno, sino también de que el interés esgrimido como factor habilitante sea legítimo en el caso 
concreto. En el caso de un interés colectivo o difuso, a los requisitos ya enunciados de a) afectación directa o indirecta por las conductas denunciadas, debemos ańadir que este debe ser b) suficientemente representativo, c) exento de conflictos de interés, y d) acreditable y protegible sin la participación individual de los asociados.

\section{Bibliografía}

Aguirrezabal Grünstein, Maite, Algunas precisiones en torno a los intereses supraindividuales (colectivos y difusos), en Revista Chilena de Derecho 33 (2006) I.

Aguirrezabal Grünstein, Maite, Capacidad y legitimación del grupo de afectados en la ley de protección al consumidor, en Revista Chilena de Derecho Privado 3I (20I8) diciembre.

BARRIos De ANGelis, Dante, Introducción al estudio del proceso. La psicología y la sociología del proceso, El Ombudsman, La defensa de los intereses difusos (Buenos Aires, Depalma, 1983).

Biblioteca del Congreso Nacional de Chile, Historia de la Ley 19.955. Sobre protección de los derechos de los consumidores.

Bujosa Vadell, Lorenzo, Artículo II. Legitimación para la defensa de derechos e intereses de consumidores y usuarios, en GómEZ DE LIAÑo GonzÁLEZ, Fernando (coordinador), La Ley de Enjuiciamiento Civil (Oviedo, Forum, 2000).

Cordón Moreno, Faustino, Anotaciones acerca de la legitimación, en Revista de Derecho Procesal Iberoamericana 2 (1979).

Cordón Moreno, Faustino, La legitimación en el proceso contencioso-administrativo (Pamplona, Ediciones Universidad de Navarra S.A., 1979).

Crane, Daniel, Optimizing Private Antitrust Enforcement, en Vanderbilt Law Review 63 (2019) 3.

De Camargo Mancuso, Rodolfo, Comentários ao código de proteção do consumidor (São Paulo, Saraiva, I99I).

Department for Business, Innovation \& Skills, Private Actions in Competition Law: A Consultation on options for reform (2012). Disponible en https://bit.ly/38ImeAp.

Department for Business, Innovation \& Skills, Private Actions in Competition Law. A consultation on options for reform - government response, (2013). Disponible en https://bit.ly/3hiH7uL.

Edmonds, Nathaniel, Associational Standing for organizations with external conflicts of interest, en The University of Chicago Law Review I69 (2002). 
Giannini, M.S., La tutela degli interessi collettivi nei procedimenti amministrativi, en A.A.V.V., Le azioni a tutela degli interessi collettivi (Padova, Padova, 1976).

HovenKAMP, Herbert, The Obama administration and section 2 of the Sherman Act, en Boston University Law Review 90 (2010).

Nagy Csongor, István, Collective actions in Europe. A comparative, economic and transsystemic analysis (Berlín, Springer, 2019).

Pellegrini Grinover, Ada, A problemática dos interesses difusos, en PeLlegrini Grinover, Ada (editora), A tutela dos interesses difusos (Sao Paulo, Max Limonad, 1984).

Romero Seguel, Alejandro, Curso de Derecho Procesal Civil, Los presupuestos procesales relativos al órgano jurisdiccional y a las partes $\left(2 .^{\mathrm{a}}\right.$ edición, Santiago, Thomson Reuters, 20I4) II.

SÁnchez, Ricardo Juan, La legitimación en el proceso civil (Pamplona, Thomson Reuters, Aranzadi, 20I4).

VAldés Prieto, Domingo, Libre competencia y monopolio (Santiago, Editorial Jurídica de Chile, 2006).

\section{SOBRE EL AUTOR}

Jaime Arancibia Mattar es abogado y doctor en Derecho por la Universidad de Cambridge, Inglaterra. Además, es profesor de Derecho Administrativo en la Facultad de Derecho de la Universidad de los Andes. Su correo electrónico es jarancibia@uandes.cl. (1) https://orcid.org/ooooOOOI-5495-5716. 
